\title{
Developing Graduate Employability for a Challenging Labour Market: the validation of the Graduate Capital Scale
}

\begin{tabular}{|r|l|}
\hline Journal: & Journal of Applied Research in Higher Education \\
\hline Manuscript ID & JARHE-04-2021-0151.R1 \\
\hline Manuscript Type: & Research Paper \\
\hline Keywords: & $\begin{array}{l}\text { Graduate Capital model, Capitals, Careers resources, Psychometric scale, } \\
\text { Validation, Measurement instrument }\end{array}$ \\
\hline \multicolumn{2}{|l}{} \\
\hline
\end{tabular}

\section{SCHOLARONE \\ Manuscripts}




\title{
Developing Graduate Employability for a Challenging Labour Market: the validation of the Graduate Capital Scale
}

\begin{abstract}
This paper introduces a new psychometric instrument, called the 'Graduate Capital Scale'; this self-reflective tool aligns closely with the five capitals within the Graduate Capital Model (Tomlinson, 2017) and has been designed for higher education students to self-assess their confidence in transitioning to the graduate labour market. In the context of this paper, this is framed around five inter-related career capitals. This approach is exemplified by the Graduate Capital Model, adopted at a UK Russell Group University as a tool to analyse and support the career preparedness of both undergraduates and postgraduate students. An overview of employability capitals is developed and then described in relation to the development of a psychometric tool 'the Graduate Capital Scale' that seeks to operationalise these capitals. We then draw on data to establish the factor structure, reliability, and validity of the tool. Finally, we consider practical applications for the Graduate Capital Model and its associated psychometric tool.
\end{abstract}

\section{Introduction: Career resources and readiness: context and challenges}

The extent to which graduates are sufficiently equipped to find suitable employment on leaving university and then able to develop sustainable career pathways has become a prevailing public policy issue across many national contexts (DBIS, 2016; CEDA, 2015). Much of the discussion on the quality and related value of a university degree has become intimately connected to how well graduates fair in the labour market and how effectively universities have prepared them for future working life (ISE, 2018). These challenges have been compounded by a changing graduate economy, including a diversification and proliferation of graduate-level occupations and skills demands. It is estimated that nearly $40 \%$ of UK graduates are working in positions that fall below graduate level in terms of skills and knowledge utilised in employment (ONS, 2019).

The problem of graduate underemployment, and also more broadly the alleged mismatches between graduate skills and those demanded by employers, has been the focus of much national policy aimed at ensuring a better fit between HE and workplaces (Bridgstock \& Jackson, 2019; Bennett, 2019). At a national policy level, stronger levers have been developed to ensure that HEIs harness provisions and practices to more effectively equip students for the demands of the labour market. At an institutional level, this agenda has led to a host of institutional approaches that have sought to raise students' employability skills so that these can both make them attractive to employers and be utilised when entering the labour market. The question 
remains over how effective the overarching policy framework and related sets of practices are in best equipping HE students for the labour market. Recent research and analysis has acknowledged that graduates' employment outcomes are influenced by wider factors beyond the acquisition and deployment of skills (Holmes, 2015, Okay-Somerville and Scholarios, 2017; Pham and Jackson, 2020). Whilst skills denote capabilities which may be attractive to employers, many of the skills which HEIs are called on to produce are demand-driven.

There has been a gradual reframing of graduates' employability development away from more formal or objective understandings towards a richer understanding of the educational, social and work-related processes and mechanisms which facilitate students' successful engagements with the labour market. The employment returns which are given primacy in definitions of successful post-HE outcomes capture only one element in what is a more complex social process (Forrier et al, 2003; McQuaid and Lynsey, 2005). Employability is influenced by broader multi-level and interactive factors, ranging from macro level movement in the supply of suitable employment opportunities to mediating factors around a graduate's social milieu. At the level of individual agency and behavioural responses, it is acknowledged that individual's negotiation into suitable employment transcends the acquisition and deployment of skills so prevalent in policy readings of graduate outcomes.

This article introduces a new psychometric instrument, called the 'Graduate Capital Scale' (hereafter GCS); this self-reflective tool aligns with a relatively recent conceptual model, the Graduate Capital Model (Tomlinson, 2017) and has been designed for higher education students to self-assess their confidence in transitioning to the graduate labour market. The scale presented here is based on the pre-existing model which has forms of graduate capital at its core based on forms of graduate capital and its items are aligned to components of this model. This makes it distinct from several other helpful graduate career readiness and employability scales that have emerged in recent times (Bennett, 2021; G. Cabalerro et al, 2020; C. Cabalerro et al, 2011), including those with a more explicit focus on competencies (Prikshat et al, 2019).

This article is based on research that has three main aims:

1. To develop measurable learning outcomes based on the Graduate Capital Model based on a sound content and face validity of a related psychometric tool aligned to this model. 
2. To explore and confirm the factor structure of the GCS by applying factor analysis.

3. To establish the internal reliability and concurrent validity of the GCS.

After outlining the conceptual basis behind the Graduate Capital Model on which the scale is grounded, the paper explains the methodological basis on which the instrument development was based. We then show data from the scale confirming the latent constructs on which each component of capital was measured. The paper finally discusses some of the wider implications this has for career development and employability policies.

\section{Literature review: understanding graduate career readiness through a graduate capitals approach}

One of the challenges in the area of graduate employability has been finding a broader notion of career readiness that engaged with graduates' immediate and longer-term employment outcomes. On this basis, all relevant stakeholders in HE, including individual graduates, can facilitate opportunities to access the kinds of outcomes they desire and make meaningful and purposive choices (Bridgstock and Jackson, 2019). Career readiness has been defined as the ability to manage the transition into the labour market and make proactive and purposive decisions towards the goal of sustaining a meaningful career pathway(s). (Tomlinson \& Nghia, 2020, p9). Central to this definition is the acknowledgment that career readiness is underpinned by salient forms of resources and career-related capitals, enabling a job candidate to negotiate initial entry and develop sustainable career pathways (Fugate et al, 2004; Clarke, 2018; Peeters et al, 2019; Tomlinson, 2017).

In their review of more recent literature on graduate employability, Artess et al (2017) conclude that the past decade has seen understanding of employability shift from a more skills-based (possessional) approach to ones which have emphasised the significant role of forms of capital and identity in mediating how graduates approach the management of their future employment outcomes. Thus, "In such an analysis the question becomes not simply about encouraging the acquisition of skills, but rather in helping students to transition from the identity of a student towards that of a graduate worker" (Artess et al, 2017, p 40). This also requires further consideration into how graduates engaged with their personal career management, including connecting different components of their educational, social and work-related experiences to emergent career goals, values and identities. The formation of career resources can empower 
an individual in terms of opening the scope of their future planning by enhancing their perceived employability and overall levels of career proactivity (Rothwell et al, 2008; Jackson \& Tomlinson, 2020) and influencing the behaviours they engage in towards fulfilling their employment goals.

Rather than conceive of career readiness as functional potentials and capabilities, namely generic employability skills, we see career readiness as sets of inter-related career-related capitals which strengthen not only an individual's profile but their wider relationship to working life, their opportunity structures and others who facilitate access. Significant to graduate career readiness is development of resources through both formal and informal dimensions of $\mathrm{HE}$ and active mobilisation and leveraging of advantageous outcomes when entering the job market. A key issue here is the enhancement of graduates' agency, reflected in an enhanced ability and propensity towards independent action and strategies for fulfilling career goals (Pham \& Jackson, 2020; Krouwel et al, 2019). There is significant scope for institutions to enhance students' career readiness through effective forms of guidance enabling graduates to reflect upon, and develop action frames towards improving their readiness through acquisition of key employability resources. This however presents challenges in a context of long-standing inequities amongst graduates (Bathmaker et al, 2016; SMCPC, 2019): graduates do not work from an equal playing field in terms of having the opportunities or know-how to develop their future employability. It therefore become even more imperative that they are supported.

\section{Dimensions of graduate capitals}

In this article, we apply the Graduate Capital Model developed by Tomlinson (2017) which defines itself as a resource-based approach to employability. There are two core dimensions to the each of the capitals presented in this model. Firstly, their main features and value they contain; and secondly, how these work in shaping an individual's potential employment outcomes. In the first instance, the properties of each capital explain their resource potentiality that contribute towards a graduate's successful employment outcomes. This rests to a large extent on the second dimension; how their utility in labour market can be attributed to specific mechanisms through which these capitals are mobilised and effected. Importantly, these capitals do not have an independent existence but instead influence the formation and mobilisation of other forms. We now examine each of these forms. 
This first level of resource encompasses graduates' knowledge, understanding and cognitive capabilities which may be both directly, or indirectly, applicable to the workplace: their human capital. Human capital is a well-established concept in labour economic, often associated with Gary Becker (1976) and on its own terms is an aggregate of how much formal education a student received and how much they can convert this into favourable labour market outcomes. In short, its value lies in a corpus of knowledge, skills and attitudes (Baartman \& De Bruijn, 2011) that add immediate value to a student's employment profile in terms of the additional cognitive value they bring to a workplace. Knowledge and skills are conceived in both specific and generic ways and vary in the extent to which they may have occupational specificity and direct application. They can also be understood to have relatively hard and soft forms - whilst in former case human capital is a hard currency denoting higher level knowledge which adds value to a graduates' employment credentials, the latter is less tangible, sometimes behavioural. This may include meta-knowledge (self-reflection on one's knowledge and ability and, more broadly, career management skills such as knowledge of job opportunities and openings or knowing how to adapt one's job profile). Graduates can utilise their human capital, making more specific links between their formal HE knowledge and that applicable in specific occupational areas, or by applying softer forms of knowledge and skills for wider career management building. Thereby presenting and demonstrating the immediate employment value of technical knowledge and leverage of improved performance productivity.

Research has also shown the influence of social capital in leveraging labour market advantages. Social capital is understood to be a resource derived from embedded sets of social relations which enable human capital to mobilised within a wider social context in which it may be utilised (Lin, 2001). Social capital is effectively a socialised form of the knowledge and skills contained within human capital as it mobilised through the social ties and networks which further enrich its value (Granovetter, 1995). Additional forms of valuable employment-related knowledge are generated through the social networks, interactions and relationships which individuals form with significant others in an employment field. Both the strong and weak ties derived through wider social networks can facilitate the enhancement of career opportunities and accessing of areas which may be denied to individuals who have less formed ties (Batistic and Tymon, 2017). 
Social capital works two-ways between graduates and employers and can be explained by a number of social mechanisms. On the job applicant side, engaging in bonding and bridging activities with employers provides valuable knowledge on how to navigate the labour market. The acquisition of further specialised and generic knowledge and skills (human capital) can be both either utilised or employed as a signal of potential over other job candidates. Additionally, this facilitates knowledge and insight that enable graduates to better decode an organisation's field dynamics and cultural make-up. Students access greater information on opportunities and openings and often crucially, access to potential hidden labour markets, plus levels of trust between a graduate and employer may be enriched (the 'good word' effect). At the demand side, employers are more likely to recruit graduates who have motivational sets, dispositions and evidence of proactivity evidenced through positive prior interactions with those graduates. Overall, there is a two-way exchange between a graduate and employer in the mobilisation of social capital which generates reciprocal value to both parties.

Social capital also helps mobilise another significant form of capital which is crucial for facilitating sense of place within a given employment field: cultural capital. Associated mainly with the work of Bourdieu (1986), this refers principally to the development and deployment of culturally-relevant knowledge, dispositions and behavioural schemas which enable individuals to navigate social fields. For those leaving formal education, this necessitates finding meaningful alignment between their profiles and their target workplaces. Whilst the value of cultural capital depends on the dynamics and rules of a given occupational area, the challenge for graduates is demonstrating cultural 'fit' to potential employers. Much research has shown that both employers and graduates pick up cultural signals of value which feeds into relative levels of anticipatory socialisation in relation to a given field (Blackmore et al, 2019; Hora, 2016; Pham et al, 2019), and which can serve as a relative (dis)advantage for different graduates. A feature of this is the embodiment of appropriate types of dispositions that signify wider organisational values, as well as set of symbolically-derived accomplishments that make graduates more distinctive in competitive job market fields.

When making connections between a graduate's career readiness, their sense of agency and their overall employability orientation, an important dimension is self-identity, notably how they approach the labour market and think about themselves as a future employee and what they believe is possible for them. This relates to the development of identity capital (see Cote, 2016), which in this context concerns the degree to which a graduate invests their sense of self 
A further psycho-social resource which graduates need for navigating successful future pathways is psychological capital, which is essentially constitutive of individuals' capacity to adapt to continued challenges in their working life, including novel situations and potential setbacks. This is closely connected to the level of adaptability graduates have for the dealing with a context of growing risk and uncertainty (Coetzee, 2017). Using the example of international graduates who have had to adapt to novel contexts in the past, Pham et al (2019) show how strong levels of adaptability enable such graduates to be more proactive in their career development, including being open to experiences and managing risks and set-backs thus minimising the impacts of potentially adverse experiences, including job rejections, periods of unemployment and adapting to novel and challenging work environments. A central component here is the development of resilience and persistence given the increased intensity of working conditions and related competition for most graduate-level jobs. Overall, it appears that graduates with well-developed psychological capital show higher levels of overall career adaptability, have stronger contingency plans and more proactively respond to a less certain or volatile graduate labour market conditions.

Having mapped out the terrain of this model (see Tomlinson, 2017 for a related overview), we now turn to the process of constructing and validating a psychometric tool that can operationalise and measure the constructs defined in the model. 


\section{Methodology \\ Development of the Graduate Capital Scale}

Our aim was to design an accessible means for students to engage with the concepts within the Graduate Capital Model. This would facilitate them to capture their current individual perceptions of their own career readiness and provide suggestions on how the student could further develop their employability. We also wanted to capture and examine at an aggregated level, data on students' self-perceptions against a range of different aspects of their employability, in order to further develop understanding of the wider student experience and to inform future careers support planning.

To achieve these goals, it was decided to develop an online self-report test, asking a number of questions relating to different aspects of the five capitals. This test would need to be easily accessible and quick to complete (taking no longer than 10-15 minutes). The test was developed so that it could be completed on a smartphone, tablet or PC. This was important, for both those self-selecting selecting students choosing to take the test (the 'careerists') (Tomlinson, 2007), and those students asked to take the test as part of their course (e.g. within a lecture), tutorial or a careers session, (thereby seeking to access those harder to reach students, or 'retreatists'). Assistance was sought from colleagues with expertise in developing digital learning tools within the university to help develop the test online.

It was important to both student uptake and perceived usefulness of the test, that students received personalised feedback once they had completed the test. Students (and indeed, people in general) enjoy discovering new insights about themselves and their current situation, and this test aimed to capitalise on this interest and curiosity. The test feedback (available from the authors) was grouped into three main categories: 'Starting Out, 'Almost there' and 'Great Progress'. Finally, the test was embedded within the Careers and Employability website, where students could access suggestions and resources to develop their employability further, based upon their test results.

To ensure the content validity of the test (i.e. that it reflected all the relevant domains of the concept being assessed (Rust and Golombrok, 2000), learning outcomes were firstly developed 
to align closely and equally to the 5 capitals outlined in the Graduate Capital Model. These learning outcomes (shown in Table 1) were then used to generate an initial set of 51 questions for the GCS. To further establish the content validity, as well as the face validity of the test (i.e. that the test is acceptable to and understood by the target population; Rust and Golombrok, 2000), expert working groups were consulted to ensure that the questions aligned closely with the Graduate Capital Model. Those consulted over the design of the test's questions included a local network of employability experts including careers staff, academic colleagues across all faculties, the Students Union, experts in digital pedagogy and academic colleagues in the discipline of psychology who had direct experience of developing psychometric tools. There was a process of reiteration to ensure that the questions were clear and correctly interpreted and also to ensure that they were accessible to suit the needs of a student population. The language used within test questions needed to be concise and straightforward, for example, "I believe my degree will improve my career prospects" or "I can identify what motivates me". A six-point likert scale was developed for each response to each question (the responses were tailored to each question - available from the authors) (see Table 2 for specific item terms).

Once the first (51-item) version of the test had been agreed, further face validity checks and qualitative usability testing was carried out by asking eight current students to 'think-aloud' and be observed as they completed the test. The combination of qualitative data collected via both direct observation and student feedback was used to ensure that both the content and structure of the test was clear. Feedback on the test was positive, with some students offering positive comments particularly on the value of reflection. Minor adjustments were made to the wording of some questions; for example, some international students were unclear what 'labour market' meant, so this was replaced with 'job market'. To explore and confirm the factor structure of the GCS and establish the internal reliability and concurrent validity of the test, three waves of data collection were carried out.

\section{Data collection study waves 1-3}

Participants in wave 1 were 478 students from across the University of Southampton who completed the GCS via the Careers and Employability Service website in the summer of 2016. $62.1 \%$ of participants identified as female and $37.9 \%$ as male. A total of $79.5 \%$ were domiciled in the UK, $11.1 \%$ within the EU, and $9.4 \%$ overseas. The majority of participants were undergraduate students $(92.5 \%)$, with $5.4 \%$ being postgraduate taught students and $2.1 \%$ were postgraduate research students. $12.6 \%$ of participants were mature students. 
A second wave of data collection was carried out in which 325 students competed the GCS, also via the Careers and Employability Service website in spring 2018. In this group, participants were predominantly female $(76.9 \%$ female, $23.1 \%$ male), and were mainly undergraduate students $(73.5 \%$ undergraduate, $23.4 \%$ postgraduate taught, and $3.1 \%$ postgraduate research students), with $36.3 \%$ being mature students. A total of $67.4 \%$ were domiciled in the UK, $7.7 \%$ within the EU, and $24.9 \%$ from overseas.

Further data were collected in a third wave in an additional sample later in the spring of 2018. In this wave, a total of 698 participants took part in the study, of which $596(85 \%)$ identified as female and 97 (14\%) identified as male (2 participants identified as 'other'). The age range was 18-52 $($ Mean $=20.10, \mathrm{SD}=2.86)$, with $182(26 \%)$ mature students. Participants were primarily undergraduate students: 287 (41\%) were in their first year, 205 (29\%) were second year, and 201 (29\%) were in their final year. The third wave tested the concurrent validity of the GCS against the 16-item Self-Perceived Employability Scale (SPES; Rothwell, Herbert, \& Rothwell, 2008). The SPES was a comparable measure for concurrent validity as it is a validated measure and both the SPES and GCS tap into student's self-perceptions about their employability. As well as an overarching scale, the SPES can be broken down into internal employability (six items) and external employability (10 items). The internal employability subscale included items such as "I regard my academic work as top priority" and the external employability subscale included items such as "Employers are eager to employ graduates from my university", and is scored on a five-point Likert scale where one is "Strongly disagree" and five is "Strongly agree". Gender differences were also explored.

\section{Table 1 here.}

\section{Findings}

\section{Wave 1: Exploratory Factor Analysis and internal reliability.}

To test the factor structure and internal reliability of the GCS, data were analysed using IBM SPSS Statistics for Windows (Version 26). Exploratory factor analysis using principal axis factoring with direct oblimin oblique rotation was initially carried out on each of the five capitals in separate analyses, as they are theoretically five distinct constructs that are not expected to be related to each other (this was supported by the inspection of a correlation matrix which showed that the majority of items were correlated at 0.1 or less with other items not in the same hypothesised capital). The results of the EFA are given in Table 2 and show that two 
separate factors were identified for Human, Social and Cultural Capitals, and single factors best fit the Identity and Psychological Capitals. Nine items were removed from the factor analysis due to low communalities, or high negative skewness. However, three of these were retained and are recommended to be used in future research as stand-alone single items in the GCS (one each in the Human, Identity and Psychological Capitals), as they are conceptually meaningful items. Reliability analyses for each factor was carried out using Cronbach's alpha, and determined that all the subscales had a good internal reliability, with alpha values ranging from .73 to .86 (individual values shown in Table 2).

\section{Table 2 here.}

\section{Wave 2: Confirmatory Factor Analysis}

A confirmatory factor analysis with maximum likelihood estimation was used to analyse whether the factor structures for each of the five capitals proposed in the Exploratory Factor Analysis could be supported. Data were analysed using IBM SPSS AMOS (version 26). The CFA results identified that no further items needed to be removed, and confirmed that the models proposed by the EFA showed better fit to the data than the null, unmodified models (see Table 3 for CFA goodness of fit indices). Although the chi-squares are significant (which is common in larger sample sizes, so should not be considered to be problematic without consideration of other indicators Kenny \& McCoach, 2003; Babyak and Green, 2010), the CFI values are above 0.95 the TLI scores are close to or above .95 , and the RMSEA scores are below .08 indicating an acceptable fit in these indicators (Byrne, 2010). The goodness of fit index for each model was significantly improved by co-varying some of the error terms within each factor. The correlations between each of the factors and the three retained single items, along with the means and standard deviations are shown in Table 4.

\section{Table 3 here}

Table 4 here.

\section{Wave 3: Concurrent Validity}

Pearson's $r$ correlations were carried out between the subscales of the GCS, and the SPES internal, external, and total scales. All subscales of the GCS and SPES were significantly correlated, with the majority of correlations being in the medium to large effect size range 
(individual correlations are presented in Table 5). The high level of correlation suggests that the GCS has good concurrent validity and therefore adds to the validity of the measure. Few gender differences existed for the capitals, the only difference being found for the psychological capital (in which makes scored higher than female $[t(131)=-2.60, p=.010]$ ), and the identity capital single item (personal values) in which females scored higher than males $(t(123)=2.35, p=.021])$.

\section{Table 5 here}

\section{Discussion, implications and ways forward}

In this article we have further developed the terrain for approaching graduate employability as a resource-based problem which graduating students are in a potential position to enhance during their time in HE and beyond. Our conceptualisation connects to a wider body of interlinked theorising on employability which has shown this to be a dynamic and processual dimension entailing some levels of proactivity and agency in navigating the challenges of postHE transitions. Our approach resonates with the general theme of other career development and employability researchers (Forrier and Sels, 2003; Fugate et al, 2004; Clarke, 2018; Peeters et al, 2019; Bathmaker, 2021) who have demonstrated how a resource-based approach helps integrate personal and contextual factors in shaping career-related outcomes.

The main contribution in this article has been to validate a scale which sought to operationalise the capital dimensions of the model and to show which items loaded strongly onto the overarching features of these dimensions. The scale has been originally developed to provide empirical value to a theoretically rich approach to graduate career development; but also more significantly, to be potentially used as an evaluative and career readiness tool that practitioners and graduates can utilise within HE settings. The results confirm that capitals are a salient feature in terms of how graduating students frame and potentially perceive their employability and can be used as a basis to frame how ready and equipped graduates are on entering the job market. Within each capital, the exploratory factor analysis showed several core subdimensions. When employability is framed in terms of harder currencies - human capital- we have shown the continued value of degree-related knowledge and skills as a fundamental building block of graduates' employability. However, a significant and related component here 
are the more generic forms of career-building skills which help graduates navigate different job market fields. In term of social capital dynamics, the significance of improved knowledge of the job market field (including employer contacts, organisational gatekeepers) stands out, as does the facilitating role of social networks for brokering better job market insight; in particular, opportunity awareness.

The scale has further added confirmatory value to less developed and empirically-tested ideas around identity and psychological capitals. The scale results indicate the significance of relative levels of identity development and how they contribute towards graduates' perceived employment readiness. The main strength here is the potential development of a future self, entailing strong levels career exploration, motivation and insight. The development and presentation of an emerging professional identity that forms part of how graduates construct their place within given occupational spaces has salience in how they make claims about what kind of future employee they will be.

In term of the final dimension, significant issues arise concerning students' capacity to withstand so-called 'career shocks' (Akkermans et al, 2018) and transitioning to new and destabilising job settings. Proactive coping strategies are likely to figure large here, including converting failure into learning episodes, contingency planning and constructive engagement with gatekeepers. There is also considerable overlap and inter-connection between different resources: building resource capacity in one area of a graduate's life can embolden other resources. For example, enhancing an individuals' resilience or career insight can provide better scope for them to follow-through emerging social ties, which in turn can provide a channel to stronger insight on the cultural dynamics and expectations of workplaces.

We acknowledge some limitations to this study. Firstly, the respondents of this survey were based in a specific English university comprised of mainly academically high-achieving and higher socio-economic students. Such individuals are likely to be in possession of crucial resources through wider life experiences beyond HE. However, there is considerable scope for this tool to be applied to diverse, heterogeneous students given the need to improve understanding of the career needs and challenges of potentially less advantaged students. The potential power of the Graduate Capital Scale is that it can offer a diagnostic evaluation of areas of shortage which can encourage students and those working with them to improve strategies for career building. At a fairly elementary level, this could entail work on enabling a graduate to better showcase their experiences and achievements to a target organisation. 
Additionally, research is clearly required to see how these capitals continue to be formed and deployed through their early stages and the extent to which they may be mediated and furthered by key influences in the job market field (for example, mentors, line managers, colleagues, organisational practices). Given the increased framing of employability as a processual issue that plays out over time and context, further research will need to explore capitals formation during the early stages of graduates' career development including through workplaces and beyond.

\section{Practical applications}

The Graduate Capital Scale is already used widely throughout the authors' institution and has scope to be applied elsewhere. Examples of its use have included: introducing the concept of employability to large groups of students; a self-reflective tool within tutorials; as a measure of learning gain for specific interventions such as careers coaching and mentoring; and as a personal reflective tool in careers guidance. Currently, there is some debate on whether all students should complete the full or a partial version of the scale as part of their annual registration for study. Moreover, it enables the careers practitioner community to work with a more bespoke data relating to an individual student's or graduate's level of resource in terms of where they are currently at and the measures they may need to take to enhance further this.

In terms of further practical applications, the results from the Graduate Capital Scale are already being examined closely with a plan to target resources at specific groups of students who have lower levels of confidence in their career readiness. Immediate analysis of results lends itself to targeted intervention; for example, running a CV clinic for students who selfreport low levels of career management skills as part of their Human Capital. This is especially pertinent for less advantaged students (e.g. First Generation or with lower socio-economic status) who need additional support to navigate a complex labour market field, decode more hidden labour market 'rules' and cultural signals (Bathmaker et al, 2016, Bathmaker 2021; Wright and Mulvey, 2021) and develop greater career confidence and efficacy. The early indications suggest that the scale has cultural sensitivity that enables responses to be mapped against an individual's broader social characteristics which may in turn help them become acculturated for diverse types of employment fields.

Looking to the future, we will next look to compare the results from the Graduate Capital Scale with destination outcomes. In this way, we will be able to assess whether the scale has any predictive validity. Research might also usefully focus on which interventions make most 
difference to students' perceived self confidence in their career readiness. This can be mapped against a set of learning objectives or related forms of activity that students can be encouraged to undertake (see table 6). There is considerable scope for this tool to be complemented with in-depth qualitative research that could add further insight on students' and graduates' reflections on the formation and mobilisation of capitals. Likewise, there is much potential for this to be applied and adapted to diverse national contexts.

\section{Conclusions}

This article has provided quantitative validation to a previously developed resource-based model of graduate employability and provided a significant integration of theory and practice in the area of graduate employability and career readiness. This is an encouraging development given that much of the model is conceptually-loaded and, whilst some graduate may be familiar with the concepts it offers, the outcome from this measurement tool can provide a more immediate and accessible language that graduates can work with to plan for their future employment. The scale has operationalized the model through sets of items that provide an evaluative tools for students and graduates to engage in their career planning and employability management. The paper has shown that enable graduates to engage with where they are at with crucial employability resources and enables practitioners, course programme and institutions at large to develop approaches that can best support graduates towards managing the transition to employment during a challenging economic context.

\section{References}

Akkermans, J., Seibert, S \& Mol, S. (2018), "Tales of the unexpected: integrating career shocks in the contemporary careers literature", South African Journal of Industrial Psychology, Vol. 44 No.1, pp. 1-10.

Artess, J, Hooley, T. and Mellors-Bourne, R. (2017) "Employability: a review of the literature 2012-2016”, York: Higher Education Academy.

Baartman, L. K. J., \& De Bruijn, E. (2011), "Integrating knowledge, skills and attitudes: Conceptualizing learning processes towards vocational competence", Educational Research Review, Vol. 6 No.2, pp. 125-134.

Batistic, S. \& Tymon, A. (2017), "Networking behaviour, graduate employability: a social capital perspective", Education + Training, Vol. 59 No. 4, pp. 374-388.

Bathmaker, A.M. (2021), "Constructing a graduate career future: working with Bourdieu to understand transition from university to employment for students from working class background", European Journal of Education, DOI: 10.1111/ejed.12436 
Bathmaker, A.M, Ingram, N., Abrahams, J. and Waller, R. (2016), "Higher Education, Social Class and social mobility: the Degree Generation”, London: Routledge.

Babyak, M.A., Green, S B (2010), "Confirmatory Factor Analysis: An Introduction for Psychosomatic Medicine Researchers”, Psychosomatic Medicine: Vol.72 No.6, pp. 587-597

Becker, G. (1976), "Human Capital: theoretical and empirical analysis with special reference to education”, Chicago: University of Chicago Press.

Bennett, D. (2019), "Graduate employability and higher education: Past, present and future", HERDSA Review of Higher Education, Vol. 5 No. 1, pp. 31-61.

Bennett, D. and Ananthram, S. (2021), "Development, validation and deployment of the EMPLOY-ability scale", Studies in Higher Education

Blackmore, J. \& Rahimi, M. (2019), "How 'best fit' excludes international graduates from employment in Australia: a Bourdiesian perspective, Journal of Education and Work, Vol. 32 No, 5, pp. 436-448.

Bourdieu, P. (1986) "The forms of capital", in Richardson, J. (Ed.), Handbook for Theory and Research for the Sociology of Education, Greenwood, Westport, CT, pp. 241-258.

Bridgstock, R., and Jackson, D. (2019), "Strategic institutional approaches to graduate employability: Navigating meanings, measurements, and what really matters", Journal of Higher Education Policy and Management, Vol, 41 No. 4, pp. 468-484.

Byrne, B. M. (2010), "Structural equation modelling with AMOS: Basic concepts, applications, and programming". New York: Routledge. Chicago

Caballero, G., Alvarez-Gonzalez, P. and Lopez-Miguens, M.J. (2020), "How to promote the employability capital of university students? Developing and validating scales", Studies in Higher Education, Vol. 45 No. 12, pp. 2632-2652.

Caballero, C.L., Walker, A. and Fuller-Tyszkiewicz, M. (2011), "The Work Readiness Scale: developing a measure to assess the work readiness in college graduates", Journal of Teaching and Learning for Graduate Employability, Vol. 2 No. 2, pp. 41-54.

Coetzee, M. (2017), "Graduates psycho-social career preoccupations and employability capacities in the work context”, in M. Tomlinson \& L. Holmes (Eds) Graduate Employability in Context: theory, research and debate (pp 295-315), Basingstoke: Palgrave.

Cote, J. (2016), “The Identity Capital Handbook: a handbook of theory, methods, and findings". Unpublished manuscript, Department of Sociology, The University of Western Ontario, London, Ontario, Canada.

Committee for Economic Development of Australia. (2015), Australia's future workforce?, Melbourne, Australia: CEDA.

Department for Business, Innovation and Skills. (2016), "Success as a Knowledge Economy: teaching excellence, social mobility and student choice”. HMSO: London. 
Forrier, A. and Sels, L. (2003), "The concept of employability: a complex mosaic". International Journal of Human Resource Development and Management, Vol. 3 No. 2, pp. 102-124.

Fugate, M., Kinicki, A.J. and Ashforth, B.E. (2004), "Employability: a psycho-social construct, its dimensions and applications", Journal of Vocational Behavior, Vol. 65 No. 1, pp. 14-38.

Holmes, L. (2015), “Becoming a graduate: The warranting of an emergent identity". Education + Training, Vol 57, No. 2, pp. 219-238.

Hora, M. T. (2016), "Beyond the skills gap: Preparing college students for life and work". Harvard: Harvard Education Press.

Institute of Student Employers (2018) The Global Skills Gap in the 21st Century. ISE/QS Retrieved from https://ise.org.uk/page/BlogGradSkillsGapQS.

Jackson, D. \& Tomlinson, M. (2020), "Investigating the relationship between career planning, proactivity and employability perceptions amongst higher education students in uncertain labour market conditions", Higher Education, Vol. 80 No. 3, pp. 435-455.

Kenny, D.A \& Betsy McCoach, D. (2003) "Effect of the Number of Variables on Measures of Fit in Structural Equation Modeling", Structural Equation Modeling: A Multidisciplinary Journal, Vol. 10 No. 3, pp. 333-351,

Krouwel, S.J.C., van Luijn, A., \& Zweekhorst, M.B.M. (2019), "Developing a processual employability model to provide education for career self-management", Education + Training, Vol 62 No. 2, pp. 116-128.

Lin, N. 2001. Social Capital: theory and research. New Bruswick: Transaction Publishers

McQuaid R.W., and Lindsay C. 2005), "The Concept of Employability”, Urban Studies, Vol. 42 No.2, pp. 197-219.

Office for National Statistics (2019), "Over-education and hourly wages in the UK labour market", London: ONS.

Okay-Somerville, B. \& Scholaris, D. (2017), "Position, possession or process: understanding objective and subjective employability during university-to-work transitions", Studies in Higher Education, Vol 42, No. 7: 1275-1291.

Peeters, E., J. Nelissen., N. Nele De Cuyper., A. Forrier., M. Verbruggen. and H. De Witte. (2019), "Employability Capital: a conceptual framework tested through expert analysis", Journal of Career Development Vol. 46 No. 2, 79-93.

Pham, T., Tomlinson, M. \& Thompson, C. (2019), "Forms of capital and agency as mediations in negotiating employability of international graduate migrants", Globalisation, Societies and Education, Vol 17 No. 3, pp. 394-405.

Pham, T. and Jackson, D., 2020, Developing and Utilizing Employability Capitals: Graduates' Strategies across Labour Markets. Nghia, T. L. H., Pham, T., Tomlinson, M., Medica, K. \& Thompson, C. D. (eds.). 1st ed. Abingdon UK: Routledge, p. 21-40 20 p. (Routledge Research in Higher Education). 
Papifilippou, V., \& Bathmaker, A. M. (2018), "Transitions from higher education to employment among recent graduates in England: Unequal chances of achieving desired possible selves", In H. Henderson, J. Stevenson, \& A. M. Bathmaker (Eds.), Possible selves and higher education. New interdisciplinary insights (pp. 111-126). London; Routledge.

Prikshat, V., Kumar, S. \& Nankervis, A. (2019), "Work-readiness integrated competence model: Conceptualisation and scale development", Education + Training, Vol. 61 No. 5, pp. 568-589.

Rothwell, A., Herbert, I., \& Rothwell, F. (2008), "Self-perceived employability: Construction and initial validation of a scale for university students", Journal of Vocational Behavior, Vol. 73 No. 1,pp. 1-12.

Rust, J. and Golombrok, S. (2000), Modern Psychometrics: The Science of Psychological Assessment, London: Sage.

Strauss, K., Griffin, M. and Parker, S (2012), "Future work selves: how salient hoped-for identities motivate proactive career behaviors", Journal of Applied Psychology, Vol, 97 No.3, pp. 580-597.

Tomlinson, M. (2007), "Graduate employability and student attitudes and orientations to the labour market”, Journal of Education and Work, Vol. 20 No. 4. pp. 285-304.

Tomlinson, M. (2017), "Forms of graduate capital and their relationship to graduate employability", Education + Training, Vol., 59, No. 4, pp. 338-352.

Tomlinson, M. \& Nghia, T. (2020), "An overview of the current policy and conceptual landscape of graduate employability”. In T. L. H. Nghia, T. Pham, M. Tomlinson, K. Medica, \& C. D. Thompson (Eds.), Developing and utilizing employability capitals. Graduates' strategies across labour markets (pp. 1-18). London: Routledge.

Tomlinson, M. and Jackson, D. (2021), "Professional identity formation in higher education students", Studies in Higher Education, Vol. 74 No. 4, pp, 885-900.

Trede, F., R. Macklin., \& D. Bridges. (2012), "Professional identity development: a review of the higher education literature". Studies in Higher Education Vol 37 No. 3, pp. 365-384.

Wright, E \& Mulvey, B. (2021), "Internships and the graduate labour market: how uppermiddle-class students 'get ahead"”, British Journal of Sociology of Education,

DOI: $10.1080 / 01425692.2021 .1886051$ 
Table 1. Learning outcomes based on the Graduate Capital Model

\begin{tabular}{|c|c|}
\hline $\begin{array}{l}\text { Graduate } \\
\text { Capital }\end{array}$ & Learning Outcomes \\
\hline Human & $\begin{array}{l}\text { Graduates with well-developed Human Capital will be able to: } \\
\text { - Apply subject discipline knowledge and concepts } \\
\text { - Demonstrate transferable skills* relevant to the graduate job } \\
\text { market } \\
\text { - Interpret the labour market and search for opportunities } \\
\text { - Identify appropriate ways to apply for opportunities } \\
\text { - Write high quality applications and perform well in the } \\
\text { recruitment process }\end{array}$ \\
\hline Social & $\begin{array}{l}\text { Graduates with well-developed Social Capital will be able to: } \\
\text { - Identify a range of graduate-level roles } \\
\text { - Examine what is new or changing in the graduate job market } \\
\text { - Describe the key influencers in their field } \\
\text { - Recognise and capitalise on opportunities that arise } \\
\text { - Build a network of career contacts } \\
\text { - Deate an effective online presence }\end{array}$ \\
\hline Cultural & $\begin{array}{l}\text { Graduates with well-developed Cultural Capital will be able to: } \\
\text { - Demonstrate that they have added value through extra-curricular } \\
\text { activities } \\
\text { - Select and apply methods to present themselves in a professional } \\
\text { and targeted manner (on paper, on-line and in person) } \\
\text { - Assess the culture of key organisations in their chosen sector } \\
\text { - Demonstrate an awareness and sensitivity to different cultural } \\
\text { contexts and an increasingly internationalised labour market }\end{array}$ \\
\hline Identity & $\begin{array}{l}\text { Graduates with well-developed Identity Capital will be able to: } \\
\text { - Identify their skills, attributes and experiences and evaluate gaps } \\
\text { to be addressed } \\
\text { - Evaluate their self-concept, including their values and } \\
\text { motivations } \\
\text { - Appraise their strengths and areas for development } \\
\text { - Test their ideas through work experience and insights } \\
\text { - Judge their fit for roles and opportunities } \\
\text { - Select an emerging or clear career path(s) } \\
\text { - Assess their progress, identifying and recording their learning }\end{array}$ \\
\hline Psychological & $\begin{array}{l}\text { Graduates with well-developed Psychological Capital will be able to: } \\
\text { - Manage workplace uncertainty and when necessary generate } \\
\text { plans to take measured risks }\end{array}$ \\
\hline
\end{tabular}


- Demonstrate the capacity to be adaptable, able to manage setbacks, changes and transitions

- Establish personal strategies to manage workplace stresses effectively

- Construct career contingency plan(s)

Table 2: Item loadings of the pattern matrix for the five Capitals (using principal axis factoring with direct oblimin oblique rotation)

\section{Factor}

Loadings $M(S D)$

\section{Human Capital (correlation between factors $r=.40$ )}

Factor 1: Your degree skills and abilities $(\alpha=.73$; variance explained $=$ $38.9 \%)$

1. I believe my degree will improve my career prospects $\quad .81$

2. I know that my subject knowledge will be valued by employers

3. I will use my skills in future employment

Factor 2: Your career skills $(\alpha=.81$; variance explained $=17.4 \%)$

4. I know how to locate a range of information about the graduate job $\quad .72$ market

5. I can list a range of sources to find job opportunities

6. I can produce an effective $\mathrm{CV}$ and job application

7. I have an effective online career profile (e.g. LinkedIn, Indeed, .60 Monster)

8. I feel confident I can perform well at interviews

9. I feel able to perform well at assessment centres

10. Retained as single item: I can demonstrate my transferable skills

Excluded item: I am confident in my abilities to innovate and think creatively

Social Capital (correlation between factors $r=.59$ )

Factor 1: Your understanding of the job market $(\alpha=.83$; variance explained $=49.8 \%$ ) 
1. I keep up to date with the graduate job market .99

2. I can name key employers of interest to me

3. I evaluate the changing job market in my career thinking

4. I can list some graduate roles which I would be suited to

Factor 2: Your networking skills $(\alpha=.81$; variance explained $=12.9 \%)$

5. I am confident I can make the most of any opportunities for personal .81 development

6. I am confident in talking to people I don't know

7. I can recognise opportunities for personal development

8. I use my network of career contacts to inform my career planning $\quad .54$

9. I have developed contacts with employers

Cultural Capital (correlation between factors $r=.45$ )

Factor 1: Your fit with the job market $(\alpha=.87$; variance explained $=$ $49.4 \%)$

1. I know how to find out about skills, attributes and behaviours .74 required for different types of employment

2. I am able to judge whether organisations will suit me $\quad 74$

3. I know what type of role I am interested in 71

4. I feel confident I can present myself well in the sector which interests .71 me

5. I can identify what employers value most in graduates

6. I can give examples of achievements which would interest .64 employers

7. I have distinctive achievements and interests which make me stand .60 out from others

Factor 2: Your engagement with extra-curricular activities $(\alpha=.79$; variance explained $=14.7 \%$ )

8. I take part in extra-curricular activities, these might include .89 volunteering, sports, part-time work, clubs and societies

9. I can recognise and explain the value of extra-curricular activities $\quad .73$ 
Excluded item: I would be open to working internationally

Excluded item: I recognise the benefits of diversity in the workplace

\section{Identity Capital}

Factor 1: Identity Capital $(\alpha=.85$; variance explained $=49.6 \%)$

1. I can recognise roles which would suit me best

2. I can articulate my skills

3. I can identify what motivates me

4. I know what is important to me in my career

5. I have a clear career plan

6. I can list my strengths

7. I have tested my career ideas with relevant work experience

8. I keep a record of my personal development

9. Retained as single item: It is important to me that my career reflects my personal values

Excluded item: I have identified areas for personal development

\section{Psychological Capital}

Factor 1: Psychological Capital $(\alpha=.86$; variance explained $=54.7 \%)$

1. I am confident in my ability to manage change

2. I see change as an opportunity for development

3. I consider myself adaptable

4. I am able to manage setbacks

5. I enjoy taking measured risks

6. I can be persistent, despite setbacks

7. I can make plans to respond to change

8. Retained as single item: I am optimistic about gaining suitable employment 
Excluded item: I have a contingency career plan

Table 3. Goodness of fit indices for the final CFA model for each Capital.

\begin{tabular}{lccccccc}
\hline Model & $\chi^{2}$ & $d f$ & CFI & TLI & RMSEA & $\Delta \chi^{2}$ & $\Delta d f$ \\
\hline Human Capital: Two-factor model & 50.92 & 22 & .967 & .945 & .065 & 353.75 & 5 \\
Social Capital: Two-factor model & 57.40 & 24 & .969 & .954 & .068 & 216.14 & 3 \\
Cultural Capital: Two-factor model & 55.60 & 22 & .970 & .951 & .072 & 218.21 & 5 \\
Identity Capital: One-factor model & 39.67 & 16 & .98 & .96 & .071 & 160.71 & 4 \\
$\begin{array}{l}\text { Psychological Capital: One-factor } \\
\text { model }\end{array}$ & 32.54 & 13 & .98 & .96 & .077 & 21.53 & 1 \\
\hline
\end{tabular}

Note $\chi^{2}=$ chi-square; $d f=$ degrees of freedom; CFI $=$ comparative fit index; TLI $=$ TuckerLewis Index; RMSEA = root mean square error of approximation; $\Delta \chi^{2}=$ chi-square difference as compared to the one-factor unmodified model for each respective Capital; $\Delta d f=$ degrees of freedom difference as compared to the one-factor unmodified model for each respective Capital; all reported $\chi^{2}$ are significant at $p<.001$ 
Table 4. Means, Standard Deviations, and Pearson's $r$ correlations between each Capital.

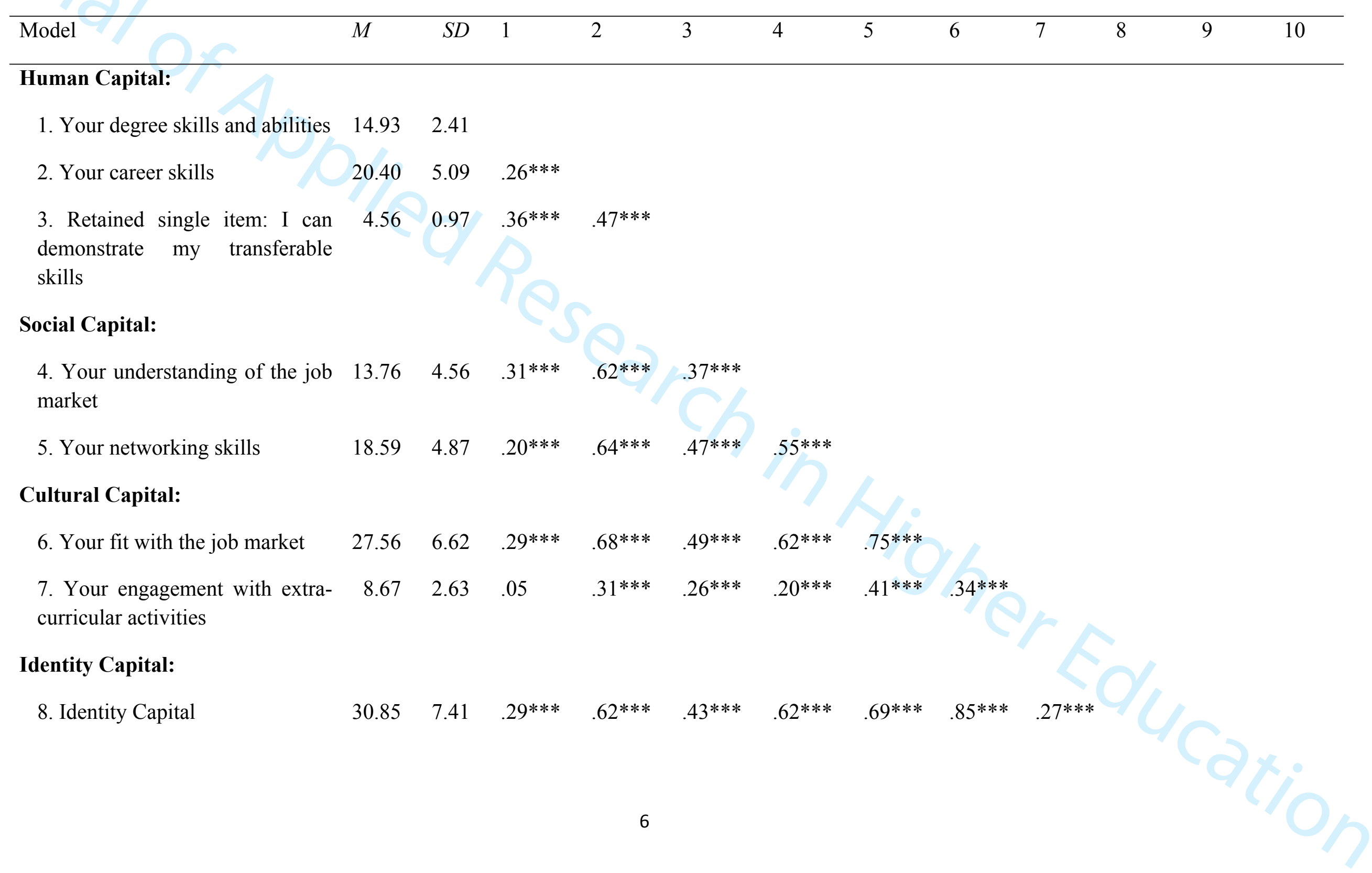


9. Retained single item: It is

4.85

1.04

$.17 * *$

$.21^{* * *}$

$.24 * * *$

$.23 * * *$

$.31 * * *$

$.39 * * *$

$.23 * * * \quad .45 * * *$ important to me that my career reflects my personal values

\section{Psychological Capital:}

10. Psychological Capital

$.27 * * *$

$.44 * * * \quad .40 * * *$

$.35 * * *$

$.50 * *$

$.48 * * *$

$.25 * * * \quad .50 * * *$

$.34 * * *$

11. Retained single item: I am

$\begin{array}{lll}4.22 & 1.28 \quad 36 * * *\end{array}$

$.40 * * * \quad .29 * * * \quad .34 * * *$

$.46 * * * \quad .49^{* * *} \quad .17 * *$

$.52^{* * *}$

$.25 * * *$

optimistic about gaining suitable employment

Note. ${ }^{* *}=p<.01, * * *=p<.001$ 
Table 5. Pearson's $r$ correlations between the GCS and the SPES.

\begin{tabular}{lllll}
\hline Model & $M$ & $S D$ & SPE & SPE \\
& & Internal & External & SPE Total \\
& & &
\end{tabular}

\section{Human Capital:}

1. Your degree skills and abilities

$14.38 \quad 2.60$

$.36^{* * *}$

$.42 * * *$

$.47 * * *$

2. Your career skills

$19.74 \quad 5.74$

$.54 * * *$

$.32 * * *$

$.49 * * *$

3. Retained single item: I can

4.79

1.05

$.43 * * *$

$.30 * * *$

$.42 * * *$

demonstrate my transferable

skills

\section{Social Capital:}

4. Your understanding of the job $11.29 \quad 4.57$ market
5. Your networking skills
$16.13 \quad 5.24$
$.50 * * *$
$.29 * * *$
$.44 * * *$

\section{Cultural Capital:}

$\begin{array}{llllll}\text { 6. Your fit with the job market } & 26.88 & 7.07 & .58^{* * *} & .37 * * * & .55^{* * * *} \\ \begin{array}{l}\text { 7. Your engagement with extra- } \\ \text { curricular activities }\end{array} & 8.12 & 2.57 & .28^{* * *} & .20^{* * * *} & .28^{* * * *} \\ \end{array}$

\section{Identity Capital}

8. Identity Capital

9. Retained single item: It is important to me that my career reflects my personal values

\section{Psychological Capital}

10. Psychological Capital

11. Retained single item: I am optimistic about gaining suitable employment
30.28

4.77

1.12

$.58 * * *$

$.36^{* * *}$

$.53 * * *$

$.28 * * *$

$.21^{* * *}$

$.28 * * *$

44

Note. ${ }^{* * *}=$ significant at $p<.001$; Effect Sizes: Small $=.10-.30$, Medium $=.30-.50$, Large >.50; SPE Internal: Mean = 21.14, $\mathrm{SD}=3.37$; SPE External: Mean $=33.46, \mathrm{SD}=4.62 ; \mathrm{SPE}$ Total: Mean $=54.62, \mathrm{SD}=6.78$. 


\title{
Developing Graduate Employability for a Challenging Labour Market: the validation of the Graduate Resources and Readiness Scale
}

\begin{abstract}
This paper introduces a new psychometric instrument, called the 'Graduate Resources and Readiness Scale'; this self-reflective tool aligns closely with the five capitals within the Graduate Capital Model (Tomlinson, 2017) and has been designed for higher education students to self-assess their confidence in transitioning to the graduate labour market. In the context of this paper, this is framed around five inter-related career capitals. This approach is exemplified by the Graduate Capital Model, adopted at a UK Russell Group University as a tool to analyse and support the career preparedness of both undergraduates and postgraduate students. An overview of employability capitals is developed and then described in relation to the development of a psychometric tool 'the Graduate Resources and Readiness Scale' that seeks to operationalise these capitals. We then draw on data to establish the factor structure, reliability, and validity of the tool. Finally, we consider practical applications for the Graduate Capital Model and its associated psychometric tool.
\end{abstract}

\section{Introduction: Career resources and readiness: context and challenges}

The extent to which graduates are sufficiently equipped to find suitable employment on leaving university and then able to develop sustainable career pathways has become a prevailing public policy issue across many national contexts (DBIS, 2016; CEDA, 2015). Much of the discussion on the quality and related value of a university degree has become intimately connected to how well graduates fair in the labour market and how effectively universities have prepared them for future working life (ISE, 2018). These challenges have been compounded by a changing graduate economy, including a diversification and proliferation of graduate-level occupations and skills demands. It is estimated that nearly $40 \%$ of UK graduates are working in positions that fall below graduate level in terms of skills and knowledge utilised in employment (ONS, 2019).

The problem of graduate underemployment, and also more broadly the alleged mismatches between graduate skills and those demanded by employers, has been the focus of much national policy aimed at ensuring a better fit between HE and workplaces (Bridgstock \& Jackson, 2019; Bennett, 2019). At a national policy level, stronger levers have been developed to ensure that HEIs harness provisions and practices to more effectively equip students for the demands of the labour market. At an institutional level, this agenda has led to a host of institutional approaches that have sought to raise students' employability skills so that these can both make them attractive to employers and be utilised when entering the labour market. The question 
remains over how effective the overarching policy framework and related sets of practices are in best equipping HE students for the labour market. Recent research and analysis has acknowledged that graduates' employment outcomes are influenced by wider factors beyond the acquisition and deployment of skills (Holmes, 2015, Okay-Somerville and Scholarios, 2017; Pham and Jackson, 2020). Whilst skills denote capabilities which may be attractive to employers, many of the skills which HEIs are called on to produce are demand-driven.

There has been a gradual reframing of graduates' employability development away from more formal or objective understandings towards a richer understanding of the educational, social and work-related processes and mechanisms which facilitate students' successful engagements with the labour market. The employment returns which are given primacy in definitions of successful post-HE outcomes capture only one element in what is a more complex social process (Forrier et al, 2003; McQuaid and Lynsey, 2005). Employability is influenced by broader multi-level and interactive factors, ranging from macro level movement in the supply of suitable employment opportunities to mediating factors around a graduate's social milieu. At the level of individual agency and behavioural responses, it is acknowledged that individual's negotiation into suitable employment transcends the acquisition and deployment of skills so prevalent in policy readings of graduate outcomes.

This article introduces a new psychometric instrument, called the 'Graduate Resources and Readiness Scale' (GRRS); this self-reflective tool aligns with a relatively recent conceptual model, the Graduate Capital Model (Tomlinson, 2017) and has been designed for higher education students to self-assess their confidence in transitioning to the graduate labour market. The scale presented here is based on the pre-existing model which has forms of graduate capital at its core based on forms of graduate capital and its items are aligned to components of this model. This makes it distinct from several other helpful graduate career readiness and employability scales that have emerged in recent times (Bennett, 2021; G. Cabalerro et al, 2020;

C. Cabalerro et al, 2011).

This article is based on research that has three main aims:

1. To develop measurable learning outcomes based on the Graduate Capital Model based on a sound content and face validity of a related psychometric tool aligned to this model. 
2. To explore and confirm the factor structure of the GRRS by applying factor analysis.

3. To establish the internal reliability and concurrent validity of the GRRS.

After outlining the conceptual basis behind the Graduate Capital Model on which the scale is grounded, the paper explains the methodological basis on which the instrument development was based. We then show data from the scale confirming the latent constructs on which each component of capital was measured. The paper finally discusses some of the wider implications this has for career development and employability policies.

\section{Literature review: understanding graduate career readiness through a graduate capitals approach}

One of the challenges in the area of graduate employability has been finding a broader notion of career readiness that engaged with graduates' immediate and longer-term employment outcomes. On this basis, all relevant stakeholders in HE, including individual graduates, can facilitate opportunities to access the kinds of outcomes they desire and make meaningful and purposive choices (Bridgstock and Jackson, 2019). Career readiness has been defined as the ability to manage the transition into the labour market and make proactive and purposive decisions towards the goal of sustaining a meaningful career pathway(s). (Tomlinson \& Nghia, 2020, p9). Central to this definition is the acknowledgment that career readiness is underpinned by salient forms of resources and career-related capitals, enabling a job candidate to negotiate initial entry and develop sustainable career pathways (Fugate et al, 2004; Clarke, 2018; Peeters et al, 2019; Tomlinson, 2017).

In their review of more recent literature on graduate employability, Artess et al (2017) conclude that the past decade has seen understanding of employability shift from a more skills-based (possessional) approach to ones which have emphasised the significant role of forms of capital and identity in mediating how graduates approach the management of their future employment outcomes. Thus, "In such an analysis the question becomes not simply about encouraging the acquisition of skills, but rather in helping students to transition from the identity of a student towards that of a graduate worker" (Artess et al, 2017, p 40). This also requires further consideration into how graduates engaged with their personal career management, including connecting different components of their educational, social and work-related experiences to emergent career goals, values and identities. The formation of career resources can empower 
an individual in terms of opening the scope of their future planning by enhancing their perceived employability and overall levels of career proactivity (Rothwell et al, 2008; Jackson $\&$ Tomlinson, 2020) and influencing the behaviours they engage in towards fulfilling their employment goals.

Rather than conceive of career readiness as functional potentials and capabilities, namely generic employability skills, we see career readiness as sets of inter-related career-related capitals which strengthen not only an individual's profile but their wider relationship to working life, their opportunity structures and others who facilitate access. Significant to graduate career readiness is development of resources through both formal and informal dimensions of $\mathrm{HE}$ and active mobilisation and leveraging of advantageous outcomes when entering the job market. A key issue here is the enhancement of graduates' agency, reflected in an enhanced ability and propensity towards independent action and strategies for fulfilling career goals (Pham \& Jackson, 2020; Krouwel et al, 2019). There is significant scope for institutions to enhance students' career readiness through effective forms of guidance enabling graduates to reflect upon, and develop action frames towards improving their readiness through acquisition of key employability resources. This however presents challenges in a context of long-standing inequities amongst graduates (Bathmaker et al, 2016; SMCPC, 2019): graduates do not work from an equal playing field in terms of having the opportunities or know-how to develop their future employability. It therefore become even more imperative that they are supported.

\section{Dimensions of graduate capitals}

In this article, we apply the Gradate Capital Model developed by Tomlinson (2017) which defines itself as a resource-based approach to employability. There are two core dimensions to the each of the capitals presented in this model. Firstly, their main features and value they contain; and secondly, how these work in shaping an individual's potential employment outcomes. In the first instance, the properties of each capital explain their resource potentiality that contribute towards a graduate's successful employment outcomes. This rests to a large extent on the second dimension; how their utility in labour market can be attributed to specific mechanisms through which these capitals are mobilised and effected. Importantly, these capitals do not have an independent existence but instead influence the formation and mobilisation of other forms. We now examine each of these forms. 
This first level of resource encompasses graduates' knowledge, understanding and cognitive capabilities which may be both directly, or indirectly, applicable to the workplace: their human capital. Human capital is a well-established concept in labour economic, often associated with Gary Becker (1976) and on its own terms is an aggregate of how much formal education a student received and how much they can convert this into favourable labour market outcomes. In short, its value lies in a corpus of knowledge, skills and attitudes (Baartman \& De Bruijn, 2011) that add immediate value to a student's employment profile in terms of the additional cognitive value they bring to a workplace. Knowledge and skills are conceived in both specific and generic ways and vary in the extent to which they may have occupational specificity and direct application. They can also be understood to have relatively hard and soft forms - whilst in former case human capital is a hard currency denoting higher level knowledge which adds value to a graduates' employment credentials, the latter is less tangible, sometimes behavioural. This may include meta-knowledge (self-reflection on one's knowledge and ability and, more broadly, career management skills such as knowledge of job opportunities and openings or knowing how to adapt one's job profile). Graduates can utilise their human capital, making more specific links between their formal HE knowledge and that applicable in specific occupational areas, or by applying softer forms of knowledge and skills for wider career management building. Thereby presenting and demonstrating the immediate employment value of technical knowledge and leverage of improved performance productivity.

Research has also shown the influence of social capital in leveraging labour market advantages. Social capital is understood to be a resource derived from embedded sets of social relations which enable human capital to mobilised within a wider social context in which it may be utilised (Lin, 2001). Social capital is effectively a socialised form of the knowledge and skills contained within human capital as it mobilised through the social ties and networks which further enrich its value (Granovetter, 1995). Additional forms of valuable employment-related knowledge are generated through the social networks, interactions and relationships which individuals form with significant others in an employment field. Both the strong and weak ties derived through wider social networks can facilitate the enhancement of career opportunities and accessing of areas which may be denied to individuals who have less formed ties (Batistic and Tymon, 2017). 
Social capital works two-ways between graduates and employers and can be explained by a number of social mechanisms. On the job applicant side, engaging in bonding and bridging activities with employers provides valuable knowledge on how to navigate the labour market. The acquisition of further specialised and generic knowledge and skills (human capital) can be both either utilised or employed as a signal of potential over other job candidates. Additionally, this facilitates knowledge and insight that enable graduates to better decode an organisation's field dynamics and cultural make-up. Students access greater information on opportunities and openings and often crucially, access to potential hidden labour markets, plus levels of trust between a graduate and employer may be enriched (the 'good word' effect). At the demand side, employers are more likely to recruit graduates who have motivational sets, dispositions and evidence of proactivity evidenced through positive prior interactions with those graduates. Overall, there is a two-way exchange between a graduate and employer in the mobilisation of social capital which generates reciprocal value to both parties.

Social capital also helps mobilise another significant form of capital which is crucial for facilitating sense of place within a given employment field: cultural capital. Associated mainly with the work of Bourdieu (1986), this refers principally to the development and deployment of culturally-relevant knowledge, dispositions and behavioural schemas which enable individuals to navigate social fields. For those leaving formal education, this necessitates finding meaningful alignment between their profiles and their target workplaces. Whilst the value of cultural capital depends on the dynamics and rules of a given occupational area, the challenge for graduates is demonstrating cultural 'fit' to potential employers. Much research has shown that both employers and graduates pick up cultural signals of value which feeds into relative levels of anticipatory socialisation in relation to a given field (Blackmore et al, 2019; Hora, 2019; Pham et al, 2019), and which can serve as a relative (dis)advantage for different graduates. A feature of this is the embodiment of appropriate types of dispositions that signify wider organisational values, as well as set of symbolically-derived accomplishments that make graduates more distinctive in competitive job market fields.

When making connections between a graduate's career readiness, their sense of agency and their overall employability orientation, an important dimension is self-identity, notably how they approach the labour market and think about themselves as a future employee and what they believe is possible for them. This relates to the development of identity capital (see Cote, 2016), which in this context concerns the degree to which a graduate invests their sense of self 
in their future working life, which in turn enables them to form goals and strategic choices. The ways in which they conceptualise their future careers and place in the labour market can operate as a resource that add value (or otherwise) to their overall approach and strategy. This is also largely based on the construction and of a future working self (Strauss et al, 2012; Phillipou and Bathmaker, 2018). A prospective employee's identities may be channelled, or otherwise, around specific occupational areas or more widely towards the pursuit of developing a wider place in the labour market. This is likely to encompass the values they hold and how this related to individuals' sense of who they are in relation to working life (Tomlinson \& Jackson 2021; Trede et at, 2012). The extent to which individual students personally invest themselves in future careers will determine how proactive they are in their career planning and post-university strategies. This in turn has potential to enhance career motivation and proactivity, leading potentially to higher levels of career insight, which may effectively enhance social capital and cultural capital (developing a sense of cultural connectedness with one or several employer organisations).

A further psycho-social resource which graduates need for navigating successful future pathways is psychological capital, which is essentially constitutive of individuals' capacity to adapt to continued challenges in their working life, including novel situations and potential setbacks. This is closely connected to the level of adaptability graduates have for the dealing with a context of growing risk and uncertainty (Coetzee, 2017). Using the example of international graduates who have had to adapt to novel contexts in the past, Pham et al (2019) show how strong levels of adaptability enable such graduates to be more proactive in their career development, including being open to experiences and managing risks and set-backs thus minimising the impacts of potentially adverse experiences, including job rejections, periods of unemployment and adapting to novel and challenging work environments. A central component here is the development of resilience and persistence given the increased intensity of working conditions and related competition for most graduate-level jobs. Overall, it appears that graduates with well-developed psychological capital show higher levels of overall career adaptability, have stronger contingency plans and more proactively respond to a less certain or volatile graduate labour market conditions

Having mapped out the terrain of this model (see Tomlinson, 2017 for a related overview), we now turn to the process of constructing and validating a psychometric tool that can operationalise and measure the constructs defined in the model. 


\section{Methodology \\ Development of the Graduate Resources and Readiness Scale}

Our aim was to design an accessible means for students to engage with the concepts within the Graduate Capital Model. This would facilitate them to capture their current individual perceptions of their own career readiness and provide suggestions on how the student could further develop their employability. We also wanted to capture and examine at an aggregated level, data on students' self-perceptions against a range of different aspects of their employability, in order to further develop understanding of the wider student experience and to inform future careers support planning.

To achieve these goals, it was decided to develop an online self-report test, asking a number of questions relating to different aspects of the five capitals. This test would need to be easily accessible and quick to complete (taking no longer than 10-15 minutes). The test was developed so that it could be completed on a smartphone, tablet or PC. This was important, for both those self-selecting selecting students choosing to take the test (the 'careerists') (Tomlinson, 2007), and those students asked to take the test as part of their course (e.g. within a lecture), tutorial or a careers session, (thereby seeking to access those harder to reach students, or 'retreatists'). Assistance was sought from colleagues with expertise in developing digital learning tools within the university to help develop the test online.

It was important to both student uptake and perceived usefulness of the test, that students received personalised feedback once they had completed the test. Students (and indeed, people in general) enjoy discovering new insights about themselves and their current situation, and this test aimed to capitalise on this interest and curiosity. The test feedback (available from the authors) was grouped into three main categories: 'Starting Out, 'Almost there' and 'Great Progress'. Finally, the test was embedded within the Careers and Employability website, where students could access suggestions and resources to develop their employability further, based upon their test results.

To ensure the content validity of the test (i.e. that it reflected all the relevant domains of the concept being assessed (Rust and Golombrok, 2000), learning outcomes were firstly developed 
to align closely and equally to the 5 capitals outlined in the Graduate Capital Model. These learning outcomes (shown in Table 1) were then used to generate an initial set of 51 questions for the GRRS. To further establish the content validity, as well as the face validity of the test (i.e. that the test is acceptable to and understood by the target population; Rust and Golombrok, 2000), expert working groups were consulted to ensure that the questions aligned closely with the Graduate Capital Model. Those consulted over the design of the test's questions included a local network of employability experts including careers staff, academic colleagues across all faculties, the Students Union, experts in digital pedagogy and academic colleagues in the discipline of psychology who had direct experience of developing psychometric tools. There was a process of reiteration to ensure that the questions were clear and correctly interpreted and also to ensure that they were accessible to suit the needs of a student population. The language used within test questions needed to be concise and straightforward, for example, "I believe my degree will improve my career prospects" or "I can identify what motivates me". A six-point likert scale was developed for each response to each question (the responses were tailored to each question - available from the authors) (see Table 2 for specific item terms).

Once the first (51-item) version of the test had been agreed, further face validity checks and qualitative usability testing was carried out by asking eight current students to 'think-aloud' and be observed as they completed the test. The combination of qualitative data collected via both direct observation and student feedback was used to ensure that both the content and structure of the test was clear. Feedback on the test was positive, with some students offering positive comments particularly on the value of reflection. Minor adjustments were made to the wording of some questions; for example, some international students were unclear what 'labour market' meant, so this was replaced with 'job market'. To explore and confirm the factor structure of the GRRS and establish the internal reliability and concurrent validity of the test, three waves of data collection were carried out.

\section{Data collection study waves 1-3}

Participants in wave 1 were 478 students from across the University of Southampton who completed the GRRS via the Careers and Employability Service website in the summer of 2016. $62.1 \%$ of participants identified as female and $37.9 \%$ as male. A total of $79.5 \%$ were domiciled in the UK, $11.1 \%$ within the EU, and $9.4 \%$ overseas. The majority of participants were undergraduate students $(92.5 \%)$, with $5.4 \%$ being postgraduate taught students and $2.1 \%$ were postgraduate research students. $12.6 \%$ of participants were mature students. 
A second wave of data collection was carried out in which 325 students competed the GRRS, also via the Careers and Employability Service website in spring 2018. In this group, participants were predominantly female (76.9\% female, $23.1 \%$ male), and were mainly undergraduate students $(73.5 \%$ undergraduate, $23.4 \%$ postgraduate taught, and $3.1 \%$ postgraduate research students), with $36.3 \%$ being mature students. A total of $67.4 \%$ were domiciled in the UK, $7.7 \%$ within the EU, and $24.9 \%$ from overseas.

Further data were collected in a third wave in an additional sample later in the spring of 2018. In this wave, a total of 698 participants took part in the study, of which $596(85 \%)$ identified as female and 97 (14\%) identified as male (2 participants identified as 'other'). The age range was 18-52 $($ Mean $=20.10, \mathrm{SD}=2.86)$, with $182(26 \%)$ mature students. Participants were primarily undergraduate students: 287 (41\%) were in their first year, 205 (29\%) were second year, and 201 (29\%) were in their final year. The third wave tested the concurrent validity of the GRRS against the 16-item Self-Perceived Employability Scale (SPES; Rothwell, Herbert, \& Rothwell, 2008). The SPES was a comparable measure for concurrent validity as it is a validated measure and both the SPES and GRRS tap into student's self-perceptions about their employability. As well as an overarching scale, the SPES can be broken down into internal employability (six items) and external employability (10 items). The internal employability subscale included items such as "I regard my academic work as top priority" and the external employability subscale included items such as "Employers are eager to employ graduates from my university", and is scored on a five-point Likert scale where one is "Strongly disagree" and five is "Strongly agree". Gender differences were also explored.

\section{Table 1 here.}

\section{Findings}

\section{Wave 1: Exploratory Factor Analysis and internal reliability.}

To test the factor structure and internal reliability of the GRRS, data were analysed using IBM SPSS Statistics for Windows (Version 26). Exploratory factor analysis using principal axis factoring with direct oblimin oblique rotation was initially carried out on each of the five capitals in separate analyses, as they are theoretically five distinct constructs that are not expected to be related to each other (this was supported by the inspection of a correlation matrix which showed that the majority of items were correlated at 0.1 or less with other items not in the same hypothesised capital). The results of the EFA are given in Table 2 and show that two 
separate factors were identified for Human, Social and Cultural Capitals, and single factors best fit the Identity and Psychological Capitals. Nine items were removed from the factor analysis due to low communalities, or high negative skewness. However, three of these were retained and are recommended to be used in future research as stand-alone single items in the GRRS (one each in the Human, Identity and Psychological Capitals), as they are conceptually meaningful items. Reliability analyses for each factor was carried out using Cronbach's alpha, and determined that all the subscales had a good internal reliability, with alpha values ranging from .73 to .86 (individual values shown in Table 2).

\section{Table 2 here.}

\section{Wave 2: Confirmatory Factor Analysis}

A confirmatory factor analysis with maximum likelihood estimation was used to analyse whether the factor structures for each of the five capitals proposed in the Exploratory Factor Analysis could be supported. Data were analysed using IBM SPSS AMOS (version 26). The CFA results identified that no further items needed to be removed, and confirmed that the models proposed by the EFA showed better fit to the data than the null, unmodified models (see Table 3 for CFA goodness of fit indices). Although the chi-squares are significant (which is common in larger sample sizes, so should not be considered to be problematic without consideration of other indicators Kenny \& McCoach, 2003; Babyak and Green, 2010), the CFI values are above 0.95 the TLI scores are close to or above .95 , and the RMSEA scores are below .08 indicating an acceptable fit in these indicators (Byrne, 2010). The goodness of fit index for each model was significantly improved by co-varying some of the error terms within each factor. The correlations between each of the factors and the three retained single items, along with the means and standard deviations are shown in Table 4.

Table 3 here

Table 4 here.

\section{Wave 3: Concurrent Validity}

Pearson's r correlations were carried out between the subscales of the GRRS, and the SPES internal, external, and total scales. All subscales of the GRRS and SPES were significantly correlated, with the majority of correlations being in the medium to large effect size range 
(individual correlations are presented in Table 5). The high level of correlation suggests that the GRRS has good concurrent validity and therefore adds to the validity of the measure. Few gender differences existed for the capitals, the only difference being found for the psychological capital (in which makes scored higher than female $[t(131)=-2.60, p=.010]$ ), and the identity capital single item (personal values) in which females scored higher than males $(t(123)=2.35, p=.021])$.

\section{Table 5 here}

\section{Discussion, implications and ways forward}

In this article we have further developed the terrain for approaching graduate employability as a resource-based problem which graduating students are in a potential position to enhance during their time in HE and beyond. Our conceptualisation connects to a wider body of interlinked theorising on employability which has shown this to be a dynamic and processual dimension entailing some levels of proactivity and agency in navigating the challenges of postHE transitions. Our approach resonates with the general theme of other career development and employability researchers (Forrier and Sels, 2003; Fugate et al, 2004; Clarke, 2018; Peeters et al, 2019; Bathmaker, 2021) who have demonstrated how a resource-based approach helps integrate personal and contextual factors in shaping career-related outcomes.

The main contribution in this article has been to validate a scale which sought to operationalise the capital dimensions of the model and to show which items loaded strongly onto the overarching features of these dimensions. The scale has been originally developed to provide empirical value to a theoretically rich approach to graduate career development; but also more significantly, to be potentially used as an evaluative and career readiness tool that practitioners and graduates can utilise within HE settings. The results confirm that capitals are a salient feature in terms of how graduating students frame and potentially perceive their employability and can be used as a basis to frame how ready and equipped graduates are on entering the job market. Within each capital, the exploratory factor analysis showed several core subdimensions. When employability is framed in terms of harder currencies - human capital- we have shown the continued value of degree-related knowledge and skills as a fundamental building block of graduates' employability. However, a significant and related component here 
are the more generic forms of career-building skills which help graduates navigate different job market fields. In term of social capital dynamics, the significance of improved knowledge of the job market field (including employer contacts, organisational gatekeepers) stands out, as does the facilitating role of social networks for brokering better job market insight; in particular, opportunity awareness.

The scale has further added confirmatory value to less developed and empirically-tested ideas around identity and psychological capitals. The scale results indicate the significance of relative levels of identity development and how they contribute towards graduates' perceived employment readiness. The main strength here is the potential development of a future self, entailing strong levels career exploration, motivation and insight. The development and presentation of an emerging professional identity that forms part of how graduates construct their place within given occupational spaces has salience in how they make claims about what kind of future employee they will be.

In term of the final dimension, significant issues arise concerning students' capacity to withstand so-called 'career shocks' (Akkermans et al, 2018) and transitioning to new and destabilising job settings. Proactive coping strategies are likely to figure large here, including converting failure into learning episodes, contingency planning and constructive engagement with gatekeepers. There is also considerable overlap and inter-connection between different resources: building resource capacity in one area of a graduate's life can embolden other resources. For example, enhancing an individuals' resilience or career insight can provide better scope for them to follow-through emerging social ties, which in turn can provide a channel to stronger insight on the cultural dynamics and expectations of workplaces.

We acknowledge some limitations to this study. Firstly, the respondents of this survey were based in a specific English university comprised of mainly academically high-achieving and higher socio-economic students. Such individuals are likely to be in possession of crucial resources through wider life experiences beyond HE. However, there is considerable scope for this tool to be applied to diverse, heterogeneous students given the need to improve understanding of the career needs and challenges of potentially less advantaged students. The potential power of the Graduate Resources and Readiness Scale is that it can offer a diagnostic evaluation of areas of shortage which can encourage students and those working with them to improve strategies for career building. At a fairly elementary level, this could entail work on 
enabling a graduate to better showcase their experiences and achievements to a target organisation.

Additionally, research is clearly required to see how these capitals continue to be formed and deployed through their early stages and the extent to which they may be mediated and furthered by key influences in the job market field (for example, mentors, line managers, colleagues, organisational practices). Given the increased framing of employability as a processual issue that plays out over time and context, further research will need to explore capitals formation during the early stages of graduates' career development including through workplaces and beyond.

\section{Practical applications}

The 'Graduate Resources and Readiness Scale' is already used widely throughout the authors' institution and has scope to be applied elsewhere. Examples of its use have included: introducing the concept of employability to large groups of students; a self-reflective tool within tutorials; as a measure of learning gain for specific interventions such as careers coaching and mentoring; and as a personal reflective tool in careers guidance. Currently, there is some debate on whether all students should complete the full or a partial version of the scale as part of their annual registration for study. Moreover, it enables the careers practitioner community to work with a more bespoke data relating to an individual student's or graduate's level of resource in terms of where they are currently at and the measures they may need to take to enhance further this.

In terms of further practical applications, the results from the Graduate Resources and Readiness Scale are already being examined closely with a plan to target resources at specific groups of students who have lower levels of confidence in their career readiness. Immediate analysis of results lends itself to targeted intervention; for example, running a CV clinic for students who self-report low levels of career management skills as part of their Human Capital. This is especially pertinent for less advantaged students (e.g. First Generation or with lower socio-economic status) who need additional support to navigate a complex labour market field, decode more hidden labour market 'rules' and cultural signals (Bathmaker et al, 2016, Bathmaker 2021; Wright and Mulvey, 2021) and develop greater career confidence and efficacy. The early indications suggest that the scale has cultural sensitivity that enables responses to be mapped against an individual's broader social characteristics which may in turn help them become acculturated for diverse types of employment fields. 
Looking to the future, we will next look to compare the results from the Graduate Resources and Readiness Scale with destination outcomes. In this way, we will be able to assess whether the scale has any predictive validity. Research might also usefully focus on which interventions make most difference to students' perceived self confidence in their career readiness. This can be mapped against a set of learning objectives or related forms of activity that students can be encouraged to undertake (see table 6)

\section{Conclusions}

This article has provided quantitative validation to a previously developed resource-based model of graduate employability and provided a significant integration of theory and practice in the area of graduate employability and career readiness. This is an encouraging development given that much of the model is conceptually-loaded and, whilst some graduate may be familiar with the concepts it offers, the outcome from this measurement tool can provide a more immediate and accessible language that graduates can work with to plan for their future employment. The scale has operationalized the model through sets of items that provide an evaluative tools for students and graduates to engage in their career planning and employability management. The paper has shown that enable graduates to engage with where they are at with crucial employability resources and enables practitioners, course programme and institutions at large to develop approaches that can best support graduates towards managing the transition to employment during a challenging economic context.

\section{References}

Akkermans, J., Seibert, S \& Mol, S. (2018), "Tales of the unexpected: integrating career shocks in the contemporary careers literature", South African Journal of Industrial Psychology, Vol. 44 No.1, pp. 1-10.

Artess, J, Hooley, T. and Mellors-Bourne, R. (2017) "Employability: a review of the literature 2012-2016”, York: Higher Education Academy.

Baartman, L. K. J., \& De Bruijn, E. (2011), "Integrating knowledge, skills and attitudes: Conceptualizing learning processes towards vocational competence", Educational Research Review, Vol. 6 No.2, pp. 125-134.

Batistic, S. \& Tymon, A. (2017), "Networking behaviour, graduate employability: a social capital perspective", Education + Training, Vol. 59 No. 4, pp. 374-388. 
Bathmaker, A.M. (2021), "Constructing a graduate career future: working with Bourdieu to understand transition from university to employment for students from working class background", European Journal of Education, DOI: 10.1111/ejed.12436

Bathmaker, A.M, Ingram, N., Abrahams, J. and Waller, R. (2016), "Higher Education, Social Class and social mobility: the Degree Generation”, London: Routledge.

Babyak, M.A., Green, S B (2010), "Confirmatory Factor Analysis: An Introduction for Psychosomatic Medicine Researchers”, Psychosomatic Medicine: Vol.72 No.6, pp. 587-597

Bennett, D. (2019), "Graduate employability and higher education: Past, present and future", HERDSA Review of Higher Education, Vol. 5 No. 1, pp. 31-61.

Becker, G. (1976), "Human Capital: theoretical and empirical analysis with special reference to education”, Chicago: University of Chicago Press.

Bennett, D. and Ananthram, S. (2021), "Development, validation and deployment of the EMPLOY-ability scale", Studies in Higher Education

Blackmore, J. \& Rahimi, M. (2019), “How 'best fit' excludes international graduates from employment in Australia: a Bourdiesian perspective, Journal of Education and Work, Vol. 32 No, 5, pp. 436-448.

Bourdieu, P. (1986) “The forms of capital”, in Richardson, J. (Ed.), Handbook for Theory and Research for the Sociology of Education, Greenwood, Westport, CT, pp. 241-258.

Bridgstock, R., and Jackson, D. (2019), "Strategic institutional approaches to graduate employability: Navigating meanings, measurements, and what really matters", Journal of Higher Education Policy and Management, Vol, 41 No. 4, pp. 468-484.

Byrne, B. M. (2010), "Structural equation modelling with AMOS: Basic concepts, applications, and programming". New York: Routledge. Chicago

Caballero, G., Alvarez-Gonzalez, P. and Lopez-Miguens, M.J. (2020), "How to promote the employability capital of university students? Developing and validating scales", Studies in Higher Education, Vol. 45 No. 12, pp. 2632-2652.

Caballero, C.L., Walker, A. and Fuller-Tyszkiewicz, M. (2011), "The Work Readiness Scale: developing a measure to assess the work readiness in college graduates", Journal of Teaching and Learning for Graduate Employability, Vol. 2 No. 2, pp. 41-54.

Coetzee, M. (2017), “Graduates psycho-social career preoccupations and employability capacities in the work context", in M. Tomlinson \& L. Holmes (Eds) Graduate Employability in Context: theory, research and debate (pp 295-315), Basingstoke: Palgrave.

Cote, J. (2016), “The Identity Capital Handbook: a handbook of theory, methods, and findings". Unpublished manuscript, Department of Sociology, The University of Western Ontario, London, Ontario, Canada.

Committee for Economic Development of Australia. (2015), Australia's future workforce?, Melbourne, Australia: CEDA. 
Department for Business, Innovation and Skills. (2016), "Success as a Knowledge Economy: teaching excellence, social mobility and student choice”. HMSO: London.

Forrier, A. and Sels, L. (2003), "The concept of employability: a complex mosaic". International Journal of Human Resource Development and Management, Vol. 3 No. 2, pp. 102-124.

Fugate, M., Kinicki, A.J. and Ashforth, B.E. (2004), "Employability: a psycho-social construct, its dimensions and applications", Journal of Vocational Behavior, Vol. 65 No. 1, pp. 14-38.

Holmes, L. (2015), “Becoming a graduate: The warranting of an emergent identity". Education + Training, Vol 57, No. 2, pp. 219-238.

Hora, M. T. (2019), "Beyond the skills gap: Preparing college students for life and work". Harvard: Harvard Education Press.

Institute of Student Employers (2018) The Global Skills Gap in the 21st Century. ISE/QS Retrieved from https://ise.org.uk/page/BlogGradSkillsGapQS.

Jackson, D. \& Tomlinson, M. (2020), "Investigating the relationship between career planning, proactivity and employability perceptions amongst higher education students in uncertain labour market conditions", Higher Education, Vol. 80 No. 3, pp. 435-455.

Kenny, D.A \& Betsy McCoach, D. (2003) "Effect of the Number of Variables on Measures of Fit in Structural Equation Modeling", Structural Equation Modeling: A Multidisciplinary Journal, Vol. 10 No. 3, pp. 333-351,

Krouwel, S.J.C., van Luijn, A., \& Zweekhorst, M.B.M. (2019), "Developing a processual employability model to provide education for career self-management", Education + Training, Vol 62 No. 2, pp. 116-128.

Lin, N. 2001. Social Capital: theory and research. New Bruswick: Transaction Publishers

McQuaid R.W., and Lindsay C. 2005), "The Concept of Employability”, Urban Studies, Vol. 42 No.2, pp. 197-219.

Office for National Statistics (2019), "Over-education and hourly wages in the UK labour market", London: ONS.

Okay-Somerville, B. \& Scholaris, D. (2017), "Position, possession or process: understanding objective and subjective employability during university-to-work transitions", Studies in Higher Education, Vol 42, No. 7: 1275-1291.

Peeters, E., J. Nelissen., N. Nele De Cuyper., A. Forrier., M. Verbruggen. and H. De Witte. (2019), "Employability Capital: a conceptual framework tested through expert analysis", Journal of Career Development Vol. 46 No. 2, 79-93.

Pham, T., Tomlinson, M. \& Thompson, C. (2019), "Forms of capital and agency as mediations in negotiating employability of international graduate migrants", Globalisation, Societies and Education, Vol 17 No. 3, pp. 394-405.

Pham, T. and Jackson, D., 2020, Developing and Utilizing Employability Capitals: Graduates' Strategies across Labour Markets. Nghia, T. L. H., Pham, T., Tomlinson, M., Medica, K. \& 
Thompson, C. D. (eds.). 1st ed. Abingdon UK: Routledge, p. 21-40 20 p. (Routledge Research in Higher Education).

Papifilippou, V., \& Bathmaker, A. M. (2018), “Transitions from higher education to employment among recent graduates in England: Unequal chances of achieving desired possible selves", In H. Henderson, J. Stevenson, \& A. M. Bathmaker (Eds.), Possible selves and higher education. New interdisciplinary insights (pp. 111-126). London; Routledge.

Rothwell, A., Herbert, I., \& Rothwell, F. (2008), "Self-perceived employability: Construction and initial validation of a scale for university students", Journal of Vocational Behavior, Vol. 73 No. 1,pp. 1-12.

Rust, J. and Golombrok, S. (2000), Modern Psychometrics: The Science of Psychological Assessment, London: Sage

Strauss, K., Griffin, M. and Parker, S (2012), "Future work selves: how salient hoped-for identities motivate proactive career behaviors", Journal of Applied Psychology, Vol, 97 No.3, pp. 580-597.

Tomlinson, M. (2007), "Graduate employability and student attitudes and orientations to the labour market", Journal of Education and Work, Vol. 20 No. 4. pp. 285-304.

Tomlinson, M. (2017), "Forms of graduate capital and their relationship to graduate employability", Education + Training, Vol., 59, No. 4, pp. 338-352.

Tomlinson, M. \& Nghia, T. (2020), “An overview of the current policy and conceptual landscape of graduate employability". In T. L. H. Nghia, T. Pham, M. Tomlinson, K. Medica, \& C. D. Thompson (Eds.), Developing and utilizing employability capitals. Graduates' strategies across labour markets (pp. 1-18). London: Routledge.

Tomlinson, M. and Jackson, D. (2021), "Professional identity formation in higher education students", Studies in Higher Education, Vol. 74 No. 4, pp, 885-900.

Trede, F., R. Macklin., \& D. Bridges. (2012), "Professional identity development: a review of the higher education literature". Studies in Higher Education Vol 37 No. 3, pp. 365-384.

Wright, E \& Mulvey, B. (2021), “Internships and the graduate labour market: how uppermiddle-class students 'get ahead", British Journal of Sociology of Education, DOI: 10.1080/01425692.2021.1886051 
Table 1. Learning outcomes based on the Graduate Capital Model

\begin{tabular}{|c|c|}
\hline $\begin{array}{l}\text { Graduate } \\
\text { Capital }\end{array}$ & Learning Outcomes \\
\hline Human & $\begin{array}{l}\text { Graduates with well-developed Human Capital will be able to: } \\
\text { - Apply subject discipline knowledge and concepts } \\
\text { - Demonstrate transferable skills* relevant to the graduate job } \\
\text { market } \\
\text { - Interpret the labour market and search for opportunities } \\
\text { - Identify appropriate ways to apply for opportunities } \\
\text { - Write high quality applications and perform well in the } \\
\text { recruitment process }\end{array}$ \\
\hline Social & $\begin{array}{l}\text { Graduates with well-developed Social Capital will be able to: } \\
\text { - Identify a range of graduate-level roles } \\
\text { - Examine what is new or changing in the graduate job market } \\
\text { - Describe the key influencers in their field } \\
\text { - Recognise and capitalise on opportunities that arise } \\
\text { - Build a network of career contacts } \\
\text { - Create an effective online presence } \\
\text { - Demonstrate the confidence to talk to people they do not know }\end{array}$ \\
\hline Cultural & $\begin{array}{l}\text { Graduates with well-developed Cultural Capital will be able to: } \\
\text { - Demonstrate that they have added value through extra-curricular } \\
\text { - Setivities } \\
\text { - Select and apply methods to present themselves in a professional } \\
\text { - Assess the culture of key organisations in their chosen sector } \\
\text { - Demonstrate an awareness and sensitivity to different cultural } \\
\text { contexts and an increasingly internationalised labour market }\end{array}$ \\
\hline Identity & $\begin{array}{l}\text { Graduates with well-developed Identity Capital will be able to: } \\
\text { - Identify their skills, attributes and experiences and evaluate gaps } \\
\text { to be addressed } \\
\text { - Evaluate their self-concept, including their values and } \\
\text { motivations } \\
\text { - Appraise their strengths and areas for development } \\
\text { - Test their ideas through work experience and insights } \\
\text { - Judge their fit for roles and opportunities } \\
\text { - Select an emerging or clear career path(s) } \\
\text { - Assess their progress, identifying and recording their learning }\end{array}$ \\
\hline Psychological & $\begin{array}{l}\text { Graduates with well-developed Psychological Capital will be able to: } \\
\text { - Manage workplace uncertainty and when necessary generate } \\
\text { plans to take measured risks }\end{array}$ \\
\hline
\end{tabular}


Table 2: Item loadings of the pattern matrix for the five Capitals (using principal axis factoring with direct oblimin oblique rotation)

\section{Factor}

Loadings $M(S D)$

\section{Human Capital (correlation between factors $r=.40$ )}

Factor 1: Your degree skills and abilities $(\alpha=.73$; variance explained $=$ $38.9 \%)$

1. I believe my degree will improve my career prospects

2. I know that my subject knowledge will be valued by employers

3. I will use my skills in future employment

Factor 2: Your career skills $(\alpha=.81$; variance explained $=17.4 \%)$

4. I know how to locate a range of information about the graduate job $\quad .72$ market

5. I can list a range of sources to find job opportunities

6. I can produce an effective $\mathrm{CV}$ and job application

7. I have an effective online career profile (e.g. LinkedIn, Indeed, .60 Monster)

8. I feel confident I can perform well at interviews

9. I feel able to perform well at assessment centres

10. Retained as single item: I can demonstrate my transferable skills

Excluded item: I am confident in my abilities to innovate and think creatively

Social Capital (correlation between factors $r=.59$ )

Factor 1: Your understanding of the job market $(\alpha=.83$; variance explained $=49.8 \%$ ) 
1. I keep up to date with the graduate job market

2. I can name key employers of interest to me

3. I evaluate the changing job market in my career thinking

4. I can list some graduate roles which I would be suited to

Factor 2: Your networking skills $(\alpha=.81$; variance explained $=12.9 \%)$

5. I am confident I can make the most of any opportunities for personal .81 development

6. I am confident in talking to people I don't know

7. I can recognise opportunities for personal development

8. I use my network of career contacts to inform my career planning $\quad .54$

9. I have developed contacts with employers

Cultural Capital (correlation between factors $r=.45$ )

Factor 1: Your fit with the job market $(\alpha=.87$; variance explained $=$ $49.4 \%)$

1. I know how to find out about skills, attributes and behaviours .74 required for different types of employment

2. I am able to judge whether organisations will suit me $\quad 74$

3. I know what type of role I am interested in 71

4. I feel confident I can present myself well in the sector which interests .71 me

5. I can identify what employers value most in graduates

6. I can give examples of achievements which would interest .64 employers

7. I have distinctive achievements and interests which make me stand .60 out from others

Factor 2: Your engagement with extra-curricular activities $(\alpha=.79$; variance explained $=14.7 \%$ )

8. I take part in extra-curricular activities, these might include .89 volunteering, sports, part-time work, clubs and societies

9. I can recognise and explain the value of extra-curricular activities $\quad .73$ 
Excluded item: I would be open to working internationally

Excluded item: I recognise the benefits of diversity in the workplace

\section{Identity Capital}

Factor 1: Identity Capital $(\alpha=.85$; variance explained $=49.6 \%)$

1. I can recognise roles which would suit me best

2. I can articulate my skills

3. I can identify what motivates me

4. I know what is important to me in my career

5. I have a clear career plan

6. I can list my strengths

7. I have tested my career ideas with relevant work experience

8. I keep a record of my personal development

9. Retained as single item: It is important to me that my career reflects my personal values

Excluded item: I have identified areas for personal development

\section{Psychological Capital}

Factor 1: Psychological Capital $(\alpha=.86$; variance explained $=54.7 \%)$

1. I am confident in my ability to manage change

2. I see change as an opportunity for development

3. I consider myself adaptable

4. I am able to manage setbacks

5. I enjoy taking measured risks

6. I can be persistent, despite setbacks

7. I can make plans to respond to change

8. Retained as single item: I am optimistic about gaining suitable employment 
Excluded item: I have a contingency career plan

Table 3. Goodness of fit indices for the final CFA model for each Capital.

\begin{tabular}{llllllll}
\hline Model & $\chi^{2}$ & $d f$ & CFI & TLI & RMSEA & $\Delta \chi^{2}$ & $\Delta d f$ \\
\hline Human Capital: Two-factor model & 50.92 & 22 & .967 & .945 & .065 & 353.75 & 5 \\
Social Capital: Two-factor model & 57.40 & 24 & .969 & .954 & .068 & 216.14 & 3 \\
Cultural Capital: Two-factor model & 55.60 & 22 & .970 & .951 & .072 & 218.21 & 5 \\
Identity Capital: One-factor model & 39.67 & 16 & .98 & .96 & .071 & 160.71 & 4 \\
$\begin{array}{l}\text { Psychological Capital: One-factor } \\
\text { model }\end{array}$ & 32.54 & 13 & .98 & .96 & .077 & 21.53 & 1 \\
& & & & & & &
\end{tabular}

Note. $\chi^{2}=$ chi-square; $d f=$ degrees of freedom; CFI $=$ comparative fit index; TLI $=$ TuckerLewis Index; RMSEA = root mean square error of approximation; $\Delta \chi^{2}=$ chi-square difference as compared to the one-factor unmodified model for each respective Capital; $\Delta d f=$ degrees of freedom difference as compared to the one-factor unmodified model for each respective Capital; all reported $\chi^{2}$ are significant at $p<.001$ 
Table 4. Means, Standard Deviations, and Pearson's $r$ correlations between each Capital.

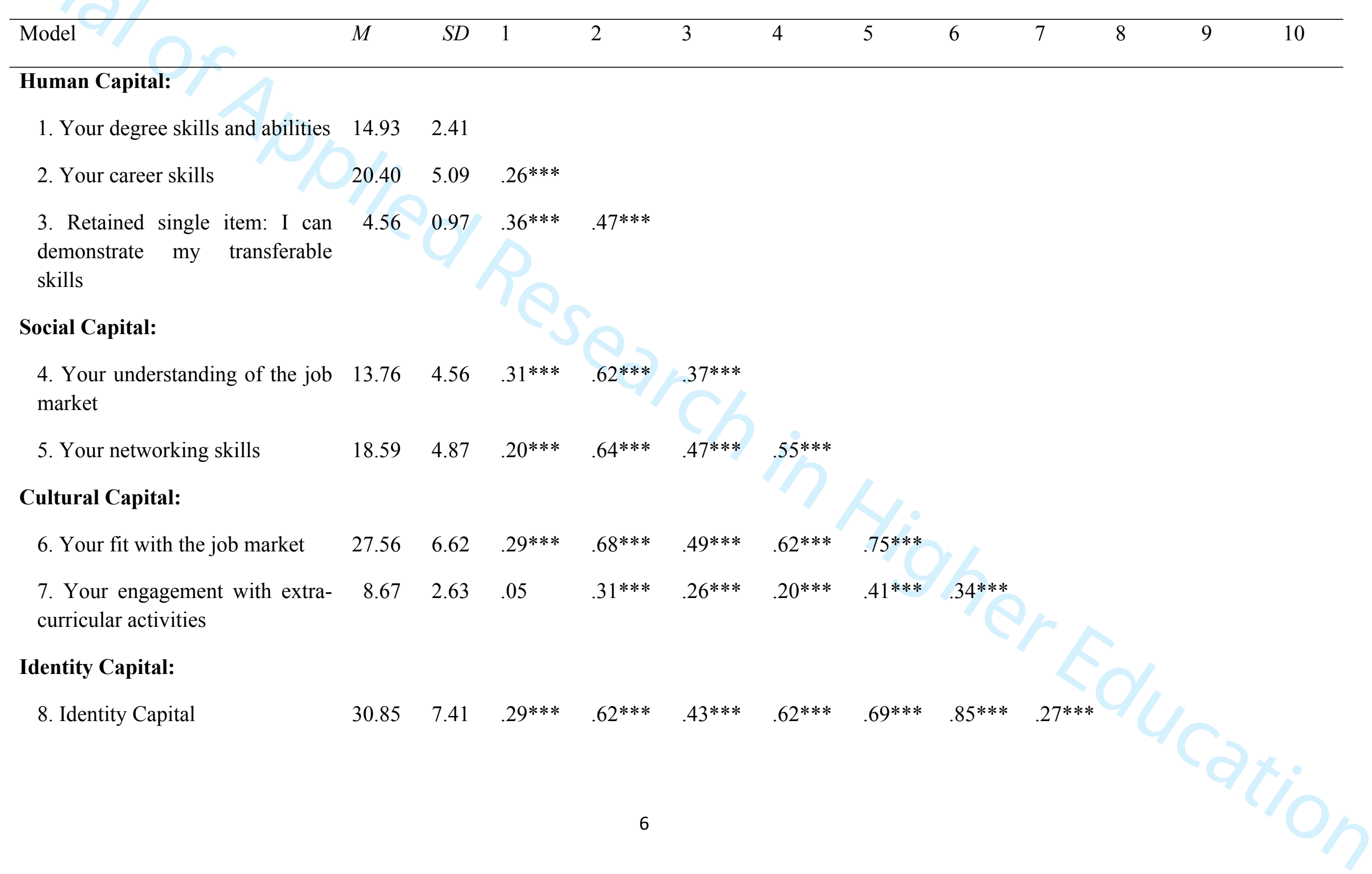


9. Retained single item: It is $4.85 \quad 1.04 \quad .17 * * \quad .21 * * * \quad .24 * * * \quad .23 * * * \quad .31 * * * \quad .39 * * * \quad .23 * * * \quad .45 * * *$ important to me that my career reflects my personal values

\section{Psychological Capital:}

10. Psychological Capital

$.27 * * *$

$.44 * * * \quad .40 * * *$

$.35 * * *$

$.50^{* * *} .48^{* * *}$

$.25 * * * \quad .50 * * *$

$.34 * * *$

11. Retained single item: I am

$4.22 \quad 1.28 \quad 36^{* * *}$

$.40 * * * \quad .29 * * * \quad .34 * * *$

$.46 * * * \quad .49^{* * *} \quad .17 * *$

$.52^{* * *}$

$.25 * * *$

optimistic about gaining suitable employment

Note. ${ }^{* *}=p<.01, * * *=p<.001$ 
Table 5. Pearson's $r$ correlations between the GRRS and the SPES.

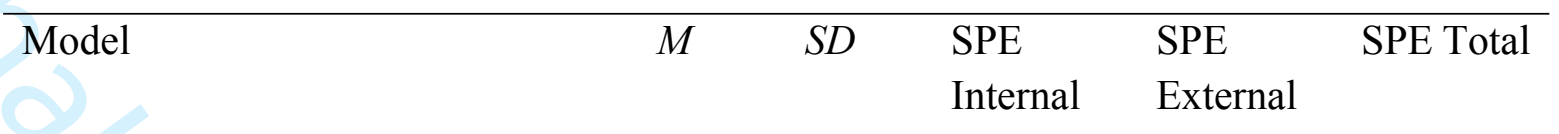

\section{Human Capital:}

1. Your degree skills and abilities

$14.38 \quad 2.60$

$.36^{* * *}$

$.42 * * *$

$.47 * * *$

2. Your career skills

$19.74 \quad 5.74$

$.54 * * *$

$.32 * * *$

$.49 * * *$

3. Retained single item: I can

4.79

1.05

$.43 * * *$

$.30 * * *$

$.42 * * *$

demonstrate my transferable

skills

\section{Social Capital:}

4. Your understanding of the job $11.29 \quad 4.57$ market
5. Your networking skills

$16.13 \quad 5.24$

$.50 * * *$

$.29 * * *$

$.44 * * *$

\section{Cultural Capital:}

\begin{tabular}{|c|c|c|c|c|}
\hline 6. Your fit with the job market & $26.88 \quad 7.07$ & $.58 * * *$ & $.37 * * *$ & $.55 * * *$ \\
\hline $\begin{array}{l}\text { 7. Your engagement with extra- } \\
\text { curricular activities }\end{array}$ & 2.57 & $.28 * * *$ & $.20 * * *$ & $.28 * * *$ \\
\hline
\end{tabular}

\section{Identity Capital}

8. Identity Capital

9. Retained single item: It is important to me that my career reflects my personal values

\section{Psychological Capital}

10. Psychological Capital

11. Retained single item: I am optimistic about gaining suitable employment
30.28

4.77

1.12

$.58 * * *$

$.36^{* * *}$

$.53 * * *$

$.28 * * *$

$.21^{* * *}$

$.28 * * *$

Note. ${ }^{* * *}=$ significant at $p<.001$; Effect Sizes: Small $=.10-.30$, Medium $=.30-.50$, Large >.50; SPE Internal: Mean = 21.14, $\mathrm{SD}=3.37$; SPE External: Mean $=33.46, \mathrm{SD}=4.62 ; \mathrm{SPE}$ Total: Mean $=54.62, \mathrm{SD}=6.78$. 
